\title{
Association between Fat-enlarged Axillary Lymph Nodes on Screening Mammography and Cardiometabolic Disease
}

\author{
Qingyuan Song ${ }^{1 *}$, Roberta M. diFlorio-Alexander ${ }^{2 *}$, Sohum D. Patel ${ }^{2}$, Ryan T. Sieberg ${ }^{2}$, Michael J. \\ Margron $^{2}$, Saif M. Ansari ${ }^{2}$, Margaret R. Karagas ${ }^{3}$, Todd A. Mackenzie ${ }^{1}$, Saeed Hassanpour ${ }^{1,3,4}$ \\ ${ }^{1}$ Department of Biomedical Data Science, Dartmouth College, 1 Medical Center Drive, Lebanon, NH 03756 \\ ${ }^{2}$ Department of Radiology, Dartmouth-Hitchcock Medical Center, 1 Medical Center Drive, Lebanon, NH 03756 \\ ${ }^{3}$ Department of Epidemiology, Dartmouth College, 1 Medical Center Drive, Lebanon, NH 03756 \\ ${ }^{4}$ Department of Computer Science, Dartmouth College, Hanover, NH 03755, USA
}

Keywords: lymph node, ectopic fat, cardiometabolic disease, screening mammography

Running Title: Fatty Lymph Nodes and Cardiometabolic Disease

\section{Corresponding Author:}

Saeed Hassanpour, $\mathrm{PhD}$

One Medical Center Drive, HB 7261

Lebanon, NH 03756

Email: Saeed.Hassanpour@dartmouth.edu

Word Count: 3080

\section{Funding:}

This research was supported in part by grants from the US National Institute of Health (R01CA249758, R01LM012837, P20GM104416).

\section{Conflicts of Interest:}

The authors have no conflicts of interest to disclose.

* These authors contributed equally to this work. 


\begin{abstract}
Objective: This study examined the association between the prevalence of cardiometabolic disease and fat-enlarged lymph nodes (LNs), identified on digital screening mammography.

Methods: A cross-sectional study on 834 women presenting for full-field digital screening mammography was conducted. The status of fat-enlarged LNs was assessed based on the size and morphology of axillary LNs from the mammograms. The prevalence of cardiometabolic disease, including type 2 diabetes mellitus (T2DM), hypertension, dyslipidemia, high blood glucose, cardiovascular disease, stroke, and non-alcoholic fatty liver disease, were retrieved from the electronic medical records.
\end{abstract}

Results: Fat-enlarged axillary LNs were associated with a high prevalence of T2DM among all women (adjusted odds ratio: 3.92, 95\% CI: [2.40, 6.60], p-value < 0.001), and in subgroups of women with and without obesity. Utilizing the status of fatty LNs improved the classification of T2DM status in addition to age and BMI (1.4\% improvement in the area under the receiver operating characteristic curve).

Conclusion: Fat-enlarge axillary LNs visualized on screening mammograms were associated with the prevalence of T2DM. If further validated with larger datasets from external institutions, fat-enlarged axillary LNs may become a novel imaging biomarker in clinical practice to improve the risk assessment of T2DM for women with screening mammography. 


\section{Introduction}

Cardiac and metabolic disease are the leading cause of death and is associated with obesity, a condition that now affects greater than $30 \%$ of adults worldwide (1-3). However, obesity is a heterogeneous condition, and patients with the same BMI have markedly different manifestations of cardiometabolic disease (4). BMI is a simple anthropometric technique for assessing generalized adiposity that does not distinguish between lean and fatty mass, nor does it differentiate between traditional subcutaneous fat and other fatty depots. The distribution of fat throughout the body is more closely correlated with cardiometabolic disease than total body fat or BMI. Existing evidence shows that the obesity phenotype is better characterized by ectopic adipose deposition within and around organs that normally contain small amounts of fat and that are not designed for excess lipid storage (4-6). Ectopic adipose within the liver, heart, muscle, and pancreas is associated with organ dysfunction and systemic adverse effects due in part to disturbances in lipid metabolism and chronic low-grade inflammation (4,6-8). A recent position statement from the International Atherosclerosis Society has acknowledged the need to develop tools to assess ectopic fat to better reflect cardiometabolic risk (5). While ectopic fat has been well-documented in multiple organ systems and is a known contributor to cardiometabolic disorders beyond BMI, few research studies have examined the link between cardiometabolic disease and ectopic fat in the human immune-lymphatic system.

Imaging techniques are critical for detecting and quantifying ectopic adipose depots in the body. Many studies have used computerized tomography (CT) and magnetic resonance imaging (MRI) to assess body composition and shown a strong correlation between ectopic fat and cardiometabolic disease in the liver, muscle, visceral cavity, pancreas, heart, and kidneys that is independent of BMI. (4-6,8). A recent prospective study further demonstrated an increased risk of cardiovascular disease and cancer along with increased ectopic fat among patients having obesity after adjusting for BMI (6). Lymph nodes (LNs) are 
medRxiv preprint doi: https://doi.org/10.1101/2021.11.16.21266413; this version posted November 20, 2021. The copyright holder for this preprint (which was not certified by peer review) is the author/funder, who has granted medRxiv a license to display the preprint in perpetuity.

It is made available under a CC-BY-NC 4.0 International license .

the small organelles of the immune-lymphatic system that can be seen on cross-sectional imaging such as

MRI and CT, and axillary LNs are also visible on screening mammograms in 50-80\% of women $(9,10)$.

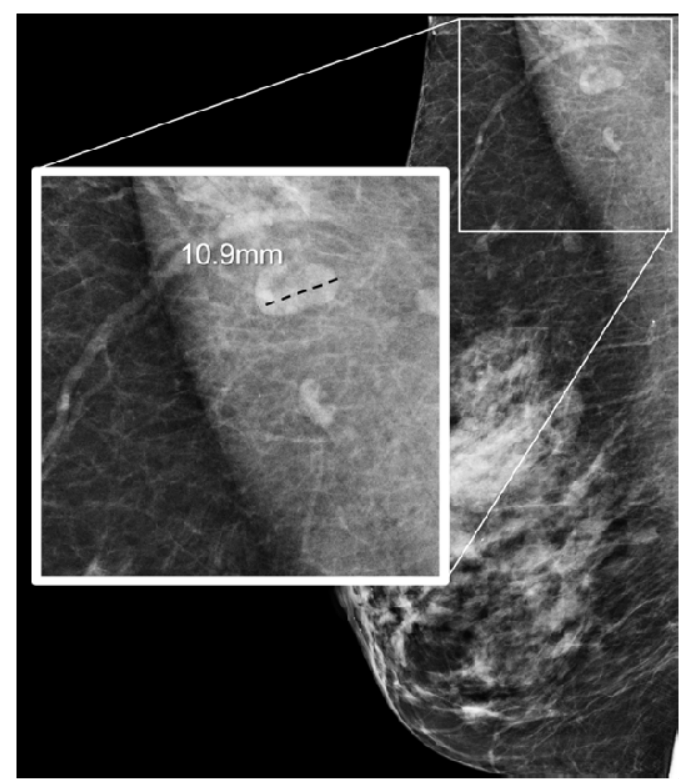

(a)

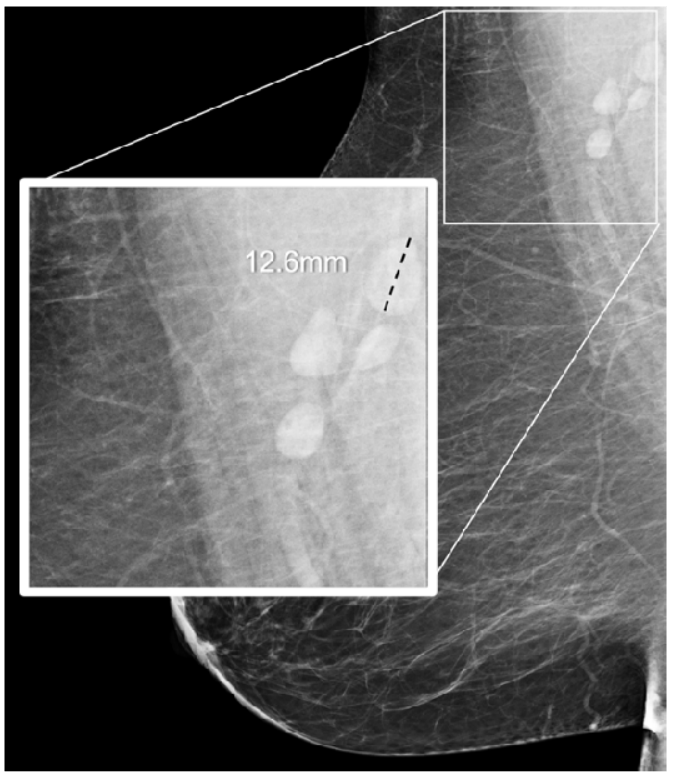

(c)

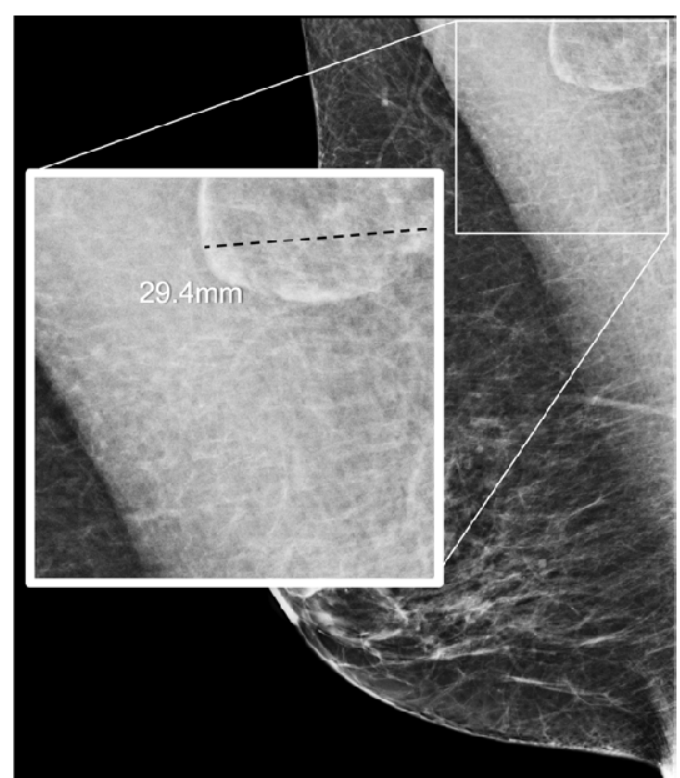

(b)

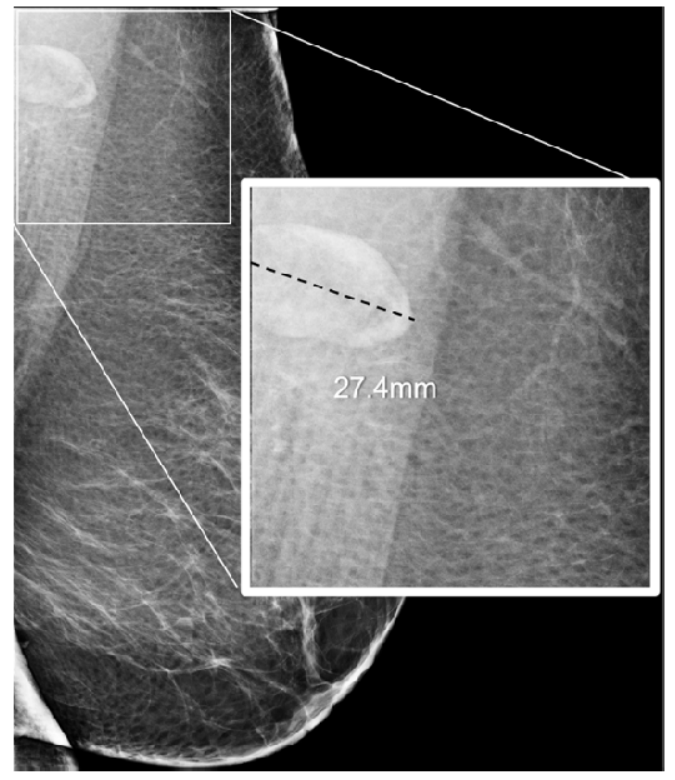

(d)

Figure 1. Benign axillary LNs demonstrate various appearances on screening mammography among women with similar age and BMI. a) Female with normal weight (60's, BMI 22) and a $10.9 \mathrm{~mm}$ normal LN; b) Female with normal weight (60's, BMI 24) and a $29.4 \mathrm{~mm}$ fatty LN; c) female with obesity (60's, BMI 40) and a $12.6 \mathrm{~mm}$ normal LN; d) female with obesity (60's, BMI 40) and a $27.4 \mathrm{~mm}$ fatty LN. 
medRxiv preprint doi: https://doi.org/10.1101/2021.11.16.21266413; this version posted November 20, 2021. The copyright holder for this

It is made available under a CC-BY-NC 4.0 International license .

Recent studies show that fat-enlarged axillary LNs on screening mammograms are associated with obesity $(9,11)$. On imaging, ectopic adipose deposition within benign LNs can be detected as fat expansion of the LN hilum as opposed to normal LNs that contain a small amount of hilar fat (Figure 1). In contrast to cortical enlargement present in nodal hyperplasia and malignant adenopathy, fat-enlarged nodes demonstrate a normal or thin, effaced cortex (9). We hypothesize that fatty LNs represent a novel type of ectopic fatty depot associated with obesity, similar to ectopic fat seen in and around other organs, and that they are associated with a higher risk of cardiometabolic disease. In this study, we aim to evaluate the relation between mammographically visualized fat-enlarged axillary LNs and features of the cardiometabolic disease, including type 2 diabetes mellitus (T2DM), hypertension, abnormal lipids, high blood glucose, cardiovascular disease (CVD), and liver steatosis in women presenting for screening mammography.

\section{Methods}

\section{Study Group and Data Collection}

This study is approved by our Institutional Review Board with a waiver of informed consent and is compliant with Health Insurance Portability and Accountability Act (HIPPA). We collected full-field digital mammogram exams of 886 females who received screening mammography between April 2018 and April 2019 from Dartmouth-Hitchcock Medical Center. The sample size was determined based on the required time and available resources for the data collection process. For each patient, the mediolateral oblique (MLO) view with the largest visible axillary LN (index node) was selected for image analysis by a breast imaging radiologist with 18 years of experience. The index node was measured along its greatest longitudinal axis and categorized as fat-enlarged or normal based on the morphology of the fatty hilum and overall node size greater than $18 \mathrm{~mm}$, using the size threshold identified in prior studies $(9,12)$. A senior radiology resident independently analyzed the screening mammograms and classified nodes as normal or fatty based using the same criteria. Cases with discrepancies were further discussed between 
medRxiv preprint doi: https://doi.org/10.1101/2021.11.16.21266413; this version posted November 20, 2021. The copyright holder for this preprint (which was not certified by peer review) is the author/funder, who has granted medRxiv a license to display the preprint in perpetuity.

It is made available under a CC-BY-NC 4.0 International license .

two reviewers until consensus was reached. We characterized the patients as fatty node cases if at least one fat-enlarged axillary LN was observed in the axilla or as normal node cases if no fatty nodes were identified on the screening mammogram.

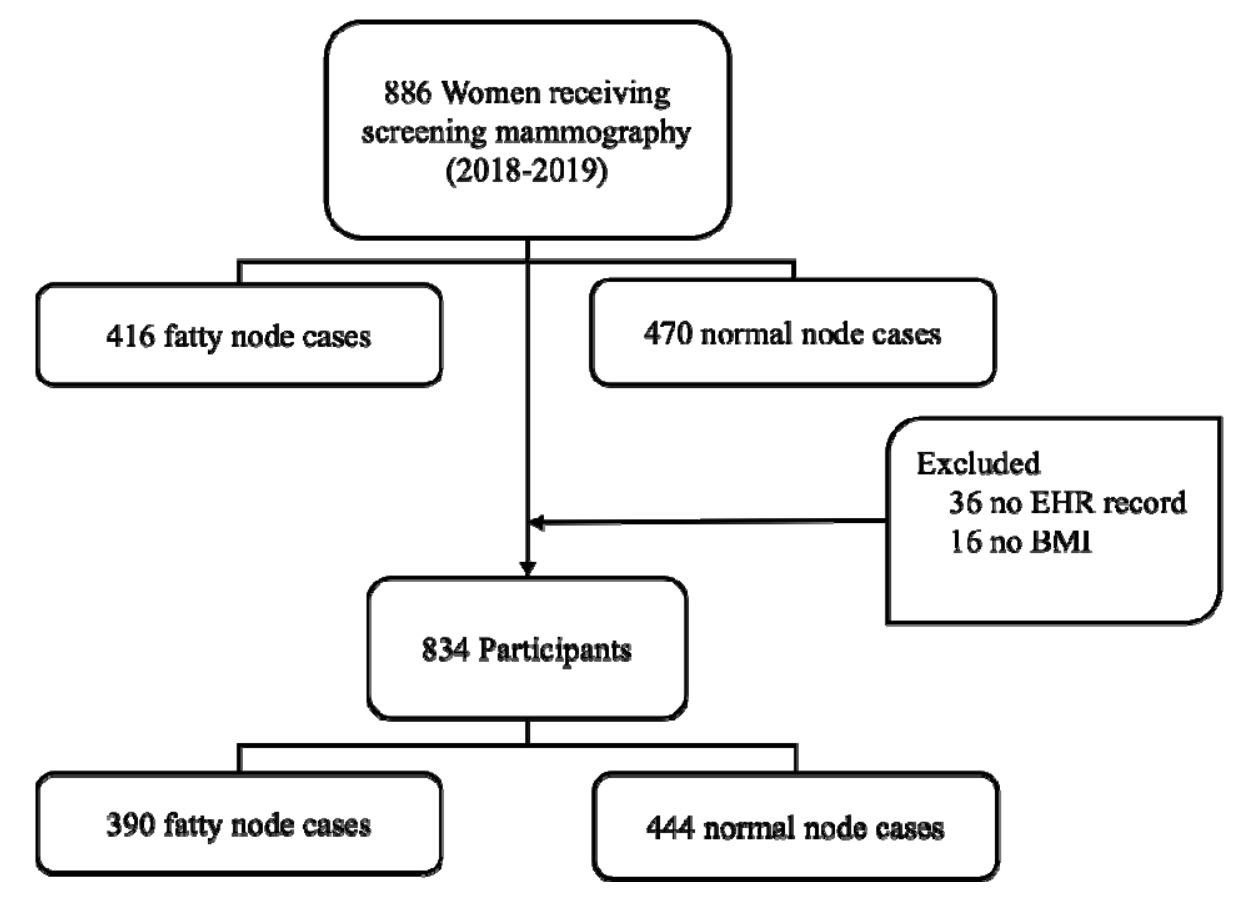

Figure 2. Data collection pipeline of the study participants.

We obtained participants' age and BMI at the time of the exam, and their cardiometabolic disease status at the date closest to the screening mammogram from the electronic medical record. The following cardiometabolic conditions were identified: T2DM, hypertension, abnormal lipids, high blood glucose, CVD, stroke, and non-alcoholic fatty liver disease (NAFLD). We labeled each disease as positive if identified in the problem list and as negative otherwise. We identified an individual as having abnormal lipids using the criteria of cholesterol >200 milligrams per deciliter (mg/dL), high-density lipoprotein (HDL) cholesterol < $40 \mathrm{mg} / \mathrm{dL}$, triglycerides $>150 \mathrm{mg} / \mathrm{dL}$, and low-density lipoprotein $(\mathrm{LDL})>100$ $\mathrm{mg} / \mathrm{dL}$. Cases with high glucose were identified with blood glucose $>100 \mathrm{mg} / \mathrm{dL}$. We used the formula weight $(\mathrm{kg}) /[\text { height }(\mathrm{m})]^{2}$ to calculated BMI if it was not available in the record. Thirty-six of the 886 cases were from outside institutions with no access to their electronic medical records, and were eliminated from the study. Sixteen patients were removed due to a lack of BMI information (or height and weight for 
medRxiv preprint doi: https://doi.org/10.1101/2021.11.16.21266413; this version posted November 20, 2021. The copyright holder for this

It is made available under a CC-BY-NC 4.0 International license .

BMI calculation). A total of 834 participants were included in this study and the flowchart of the data collection pipeline is shown in Figure 2.

\section{Statistical Analysis}

We investigated the association between fatty nodes and cardiometabolic disease in all individuals and stratified by $\mathrm{BMI}$ as having obesity $(\mathrm{BMI} \geq 30)$ and not having obesity $(\mathrm{BMI}<30)$. We estimated the crude odds ratios (ORs) between the status of fatty LNs and each cardiometabolic outcome using Fisher's exact test. The age and BMI-adjusted odds ratios were estimated by multivariate logistic regression models. We calculated the $95 \%$ confidence interval (CIs) of the odds ratio from each test and used pvalue $<0.05$ as the statistical significance level. We concluded that a cardiometabolic outcome was associated with the fat-enlarged node if the estimated odds ratio was greater than 1 with a p-value $<0.05$. The statistical analysis was conducted using R (version 4.0.3).

\section{Predicting Cardiometabolic Outcome with Fatty LN and Model Evaluation}

We evaluated fatty $\mathrm{LN}$ as a potential predictor of cardiometabolic diseases. To predict each cardiometabolic disease associated with fatty LN, we built a baseline model using age and BMI as predictors and a second model incorporating fatty LN status in the predictors. We evaluated and compared both models' ability to distinguish patients' cardiometabolic outcome status using the area under the receiver operating characteristic curve (AU-ROC). We performed bootstrapping on 5-fold crossvalidation to avoid overfitting bias. We randomly split the dataset into five folds, each containing 664 training samples (80\%) and 166 testing samples (20\%). For each fold, we randomly selected 664 samples from training samples with replacement as the training set. The baseline model and the model using fatty $\mathrm{LN}$ as a predictor were trained on the resampled training set, and the testing samples were used to evaluate the models. We repeated this process 2000 times on each fold (10000 times in total) to estimate the distribution of AU-ROC and its difference between predictions without and with fatty LN as a 
medRxiv preprint doi: https://doi.org/10.1101/2021.11.16.21266413; this version posted November 20, 2021. The copyright holder for this preprint (which was not certified by peer review) is the author/funder, who has granted medRxiv a license to display the preprint in perpetuity.

It is made available under a CC-BY-NC 4.0 International license .

predictor. Similarly, we evaluated the models in subgroups of women with and without obesity. The model evaluation workflow was conducted with Python (version 3.6.9, source) and Scikit-learn library (version 0.24 , source).

\section{Results}

(a)

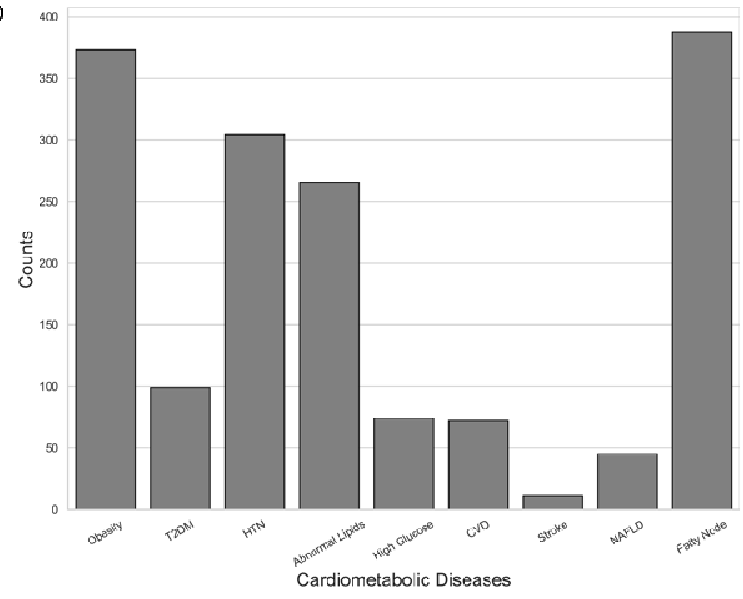

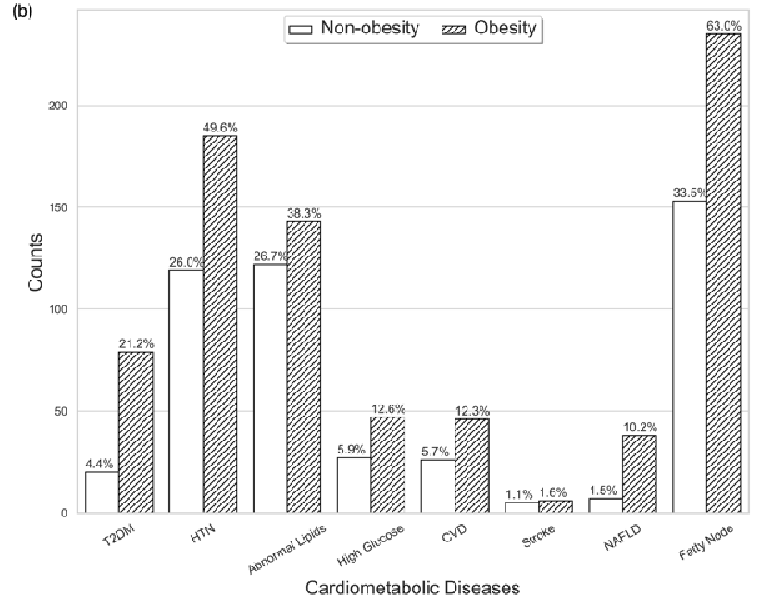

Cardiometabolic Diseases

Figure 3. Distribution of cardiometabolic diseases, NAFLD and fatty lymph nodes overall (a) and stratified by obesity status (b).

The final dataset included 834 female patients with an available problem list in the electronic medical record. Patient age ranged from 33 to 94 years at the date of exam. The distribution of cardiometabolic disease among all women and stratified by obesity is shown in Figure 3. The number of patients identified with cardiometabolic disease included 99 T2DM, 306 hypertension, 266 abnormal lipids, 74 high glucose, 72 cardiovascular disease, 11 stroke, and 45 NAFLD (Figure 3a). Four patients had type 1 diabetes and were excluded from the analysis of diabetes due to the small population. In our study, 373 (44.7\%) patients had BMI 30 and were classified as having obesity. Women who have obesity were more likely to have cardiometabolic disease and fat-enlarged nodes. However, $33.5 \%$ of women without obesity also had fat-enlarged nodes identified on screening mammography and up to $27 \%$ had underlying cardiometabolic disease, most commonly hypertension or dyslipidemia (Figure 3b). Table 1 shows the 
medRxiv preprint doi: https://doi.org/10.1101/2021.11.16.21266413; this version posted November 20, 2021. The copyright holder for this preprint (which was not certified by peer review) is the author/funder, who has granted medRxiv a license to display the preprint in perpetuity.

It is made available under a CC-BY-NC 4.0 International license .

distribution of patients' age, BMI, and status of cardiometabolic disease at the time of the screening mammogram among patients with and without fatty nodes with the difference between the two groups indicated by p-value. We found that fatty LNs are more commonly seen in older women with a higher BMI. Patients with visible fatty nodes had a higher prevalence of T2DM, hypertension, abnormal lipids, and NAFLD compared to those with normal axillary LNs.

Table 1. Demographics and status of cardiometabolic features of collected cohort, stratified by status of fatty LN.

\begin{tabular}{|l|l|l|l|}
\hline & No fatty node & Fatty node & p-value \\
\hline Total Patients (N, \%) & 444 & 390 & \\
\hline Age (mean, SD) & $61.59(10.73)$ & $64.79(10.00)$ & $<0.001$ \\
\hline BMI (mean, SD) & $27.91(6.56)$ & $32.57(7.75)$ & $<0.001$ \\
\hline Obesity (N, \%) & $138(31.1)$ & $235(60.3)$ & $<0.001$ \\
\hline Diabetes (N, \%) & & & $<0.001$ \\
\hline \multicolumn{1}{|c|}{ Type 1 } & $2(0.5)$ & $2(0.5)$ & \\
\hline Type 2 & $25(5.6)$ & $74(19.0)$ & $<0.001$ \\
\hline Hypertension (N, \%) & $130(29.3)$ & $176(45.1)$ & $<0.001$ \\
\hline Abnormal lipids (N, \%) & $119(26.8)$ & $147(37.7)$ & 0.001 \\
\hline High glucose (N, \%) & $37(8.3)$ & $37(9.5)$ & 0.644 \\
\hline CVD (N, \%) & $32(7.2)$ & $40(10.3)$ & 0.150 \\
\hline Stroke (N, \%) & $6(1.4)$ & $5(1.3)$ & 1.000 \\
\hline NAFLD (N, \%) & $15(3.4)$ & $30(7.7)$ & 0.009 \\
\hline
\end{tabular}




\section{Association between Fat-enlarged LNs and Cardiometabolic Disease}
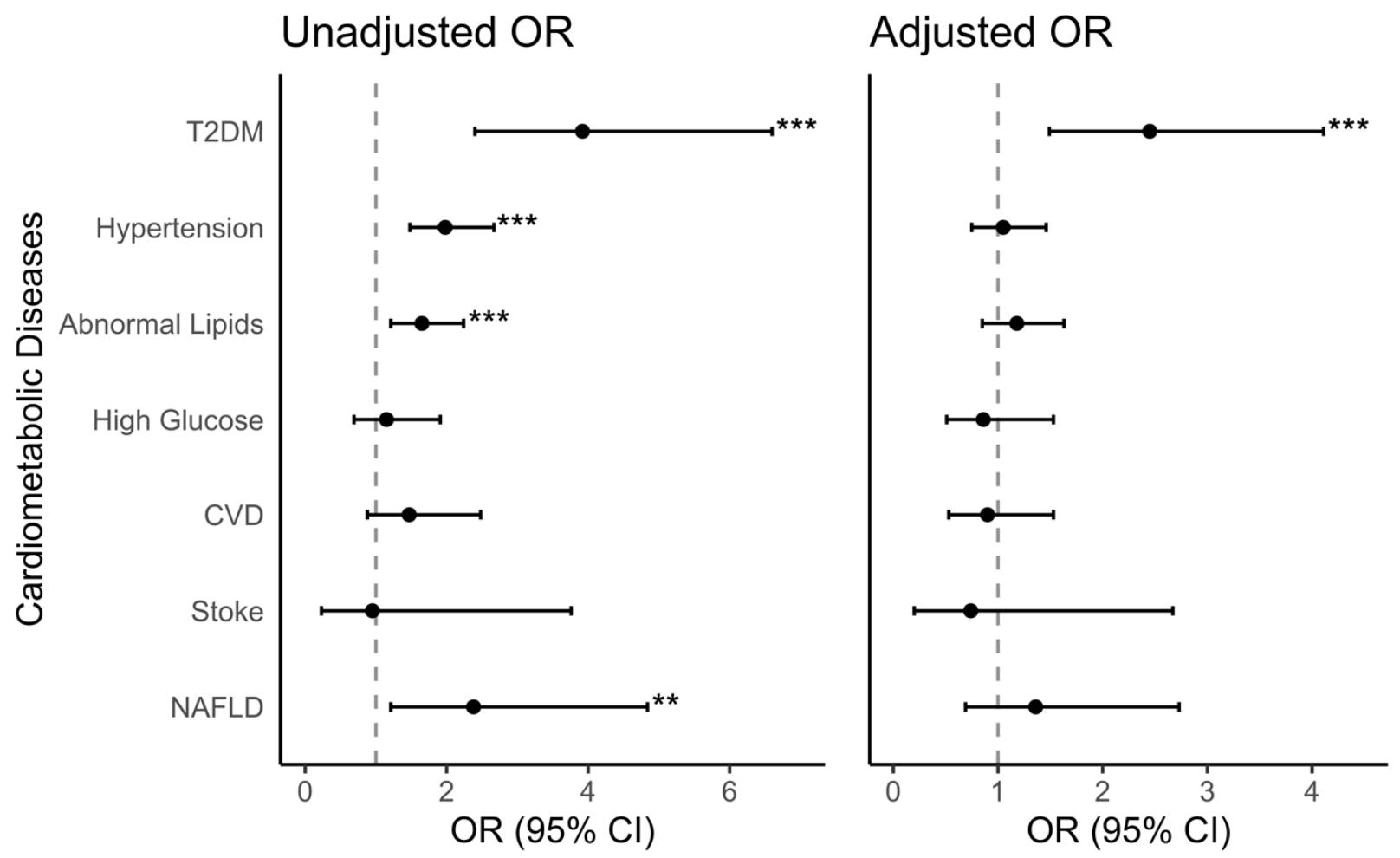

Figure 4. Association between fat-enlarged axillary LNs and collected cardiometabolic disease

status. Data are presented as unadjusted, and age and BMI-adjusted odds ratio estimates with 95\% CI between binary fatty nodes status and binary cardiometabolic disease status of all patients in our cohort. T2DM: type 2 diabetes mellitus; CVD: cardiovascular disease; NAFLD: non-alcoholic fatty liver disease. $* * * \mathrm{p}<0.001 * * \mathrm{p}<0.01 * \mathrm{p}<0.05$

Figure 4 describes the crude OR between fatty LNs and each cardiometabolic disease based on Fisher's exact test and the age and BMI-adjusted OR estimated from logistic regression, along with the corresponding p-values. The crude OR estimates show fatty node is associated with several cardiometabolic disease, including T2DM (crude OR = 3.92, p < 0.001), hypertension (crude OR = 1.98, $\mathrm{p}<0.001$ ), abnormal lipids (crude $\mathrm{OR}=1.65, \mathrm{p}<0.001$ ), and NAFLD (crude OR $=2.38, \mathrm{p}=0.008$ ). However, after adjusting for age and BMI, only T2DM remained significantly associated with fatty nodes (adjusted OR $=2.45, \mathrm{p}<0.001$ ), while age and/or BMI were significant confounders in the cases of 
medRxiv preprint doi: https://doi.org/10.1101/2021.11.16.21266413; this version posted November 20, 2021. The copyright holder for this preprint (which was not certified by peer review) is the author/funder, who has granted medRxiv a license to display the preprint in perpetuity.

It is made available under a CC-BY-NC 4.0 International license .

hypertension, abnormal lipids, and NAFLD. The detailed results for unadjusted and age and BMIadjusted analyses are shown in Supplementary Table 1.

In the analysis of subgroups with and without obesity, due to a small number of patients with stroke, we excluded the estimated odds ratio between stroke and fatty LNs. We found that T2DM was associated with fatty nodes in both groups with and without obesity. The estimated odds ratio was higher in the group without obesity (adjusted $\mathrm{OR}=2.99, \mathrm{p}=0.029$ ) compared to the group with obesity (adjusted OR $=2.03, \mathrm{p}=0.018)$ although the confidence intervals overlapped. The detailed results for obesity-stratified analysis are shown in Supplementary Table 2.

\section{Performance of T2DM Prediction with Fatty LNs Status}

The model evaluation indicated an overall improved T2DM prediction with fatty LN status. The LOOCV AU-ROC increased from 0.758 with the baseline model to 0.772 for all women when fatty LN status was included in the predictors. Adding fatty LN status to the model improved the model's discriminating capacity by $0.014,0.023$ and 0.033 in all participants, and those with and without obesity, respectively. The detailed model performance of each model is shown in Table 2.

Table 2. Comparison of AU-ROC with standard error (SE) between the baseline model (Model 1) and our model including fatty LNs (Model 2) for T2DM prediction.

\begin{tabular}{|l|l|l|l|}
\hline & AU-ROC \pm SE & Difference \pm SE \\
\hline & Model 1 & Model 2 & \\
\hline All & $0.758 \pm 0.0006$ & $0.772 \pm 0.0006$ & $0.014 \pm 0.0003$ \\
\hline With Obesity & $0.625 \pm 0.0008$ & $0.648 \pm 0.0007$ & $0.023 \pm 0.0006$ \\
\hline Without Obesity & $0.646 \pm 0.0011$ & $0.679 \pm 0.0009$ & $0.033 \pm 0.0009$ \\
\hline
\end{tabular}




\section{Discussion}

Obesity is a risk factor for cardiometabolic disease, however, up to $30 \%$ of the population with obesity is metabolically healthy without diabetes, dyslipidemia, or cardiovascular disease. In contrast, up to $30 \%$ of individuals with cardiometabolic disease do not have obesity (13). BMI is a simple anthropometric adiposity index that is effective in population-based obesity studies but does not adequately reflect the risk of cardiometabolic disease in individuals with obesity. As such, the Framingham CV risk assessment tool does not include BMI as a factor (5). Ectopic adiposity is a better predictor of cardiometabolic disease than BMI. In this study, we found a significant association between T2DM and ectopic adipose within axillary LNs visualized on screening mammograms, adjusted for age and BMI. The significant association between T2DM and fatty LN was found in groups of women with and without obesity. Our results showed that adding fatty $\mathrm{LN}$ status to our prediction model improved the prediction of T2DM in all women and subgroups with and without obesity. Our results suggest that LN hilar fat may represent a novel ectopic fat depot that is associated with a risk of T2DM independent of age and BMI among women with and without obesity and that screening mammograms may be leveraged to identify fat-enlarged LNs.

There is a strong association between T2DM and ectopic fat. Multiple studies have shown the association between ectopic visceral fat and an elevated cardiometabolic risk profile independent of BMI and total body adiposity (14). The Dallas Heart study showed that ectopic visceral fat was independently associated T2DM among adults with obesity while BMI, total body fat, and abdominal subcutaneous fat were not associated with incident diabetes mellitus (15). Additional studies have identified a higher risk of T2DM in patients with NAFLD irrespective of BMI, and a recent longitudinal study of nearly 16,000 subjects showed that ectopic fat had a markedly elevated risk for developing T2DM compared to obesity defined by BMI (16-18). In adults with and without obesity, epicardial adipose deposition has been shown to be associated with insulin resistance and T2DM (19). Our findings similarly suggest that ectopic nodal fat may be a predictor of T2DM among groups of women with and without obesity. 
It has been proposed that in this era of precision medicine, cardiovascular risk assessment among population with obesity should be refined by measures of ectopic fat deposition rather than BMI $(4,5,20)$. There is a call to develop simple, clinically applicable tools to better characterize body composition and ectopic fat deposition (5). Imaging techniques are ideally suited to the detection and measurement of ectopic fat within and around organs. Imaging exams contain information beyond their intended use as shown by the expanding field of body composition research that opportunistically identifies imaging features of adverse health outcomes on CT and MRI scans obtained for other indications (21). Imaging studies are particularly useful in the evaluation of ectopic fat deposition as they provide the ability to measure specific fat depots within and around organs and vessels, a capability that is not possible with anthropometric tools such as BMI. CT, MRI, and ultrasound can be used to assess and evaluate LN morphology, however these imaging modalities are more expensive than mammography. Furthermore, screening mammograms are performed in the majority of adult women in the United States and Europe, and the cost is widely covered by most insurance carriers (22-25). This makes opportunistic axillary node evaluation an ideal preliminary step in future research assessing the association between fat-enlarged LNs and cardiometabolic disease.

There are several proposed mechanisms for the adverse health effects associated with ectopic fat deposition in other organs that may contribute to the association between nodal ectopic adipose and diabetes seen in our study. Fatty nodes are considered a benign anatomic variant in contrast to metastatic lymphadenopathy. However, a large body of evidence has shown that fat is not inert, and more importantly, that ectopic fat is associated with chronic inflammation, dysregulated lipid metabolism, and altered adipokine secretion that may lead to local organ dysfunction and systemic adverse effects $(4,6-$ $8,13,15,17)$. While small physiologic amounts of hilar nodal fat may protect traversing vessels and lymphatics, a large volume of fat may impair nodal function by compressing hilar structures, particularly 
medRxiv preprint doi: https://doi.org/10.1101/2021.11.16.21266413; this version posted November 20, 2021. The copyright holder for this

It is made available under a CC-BY-NC 4.0 International license .

low resistance venous and lymphatic drainage, as seen with ectopic fat deposition in the renal sinus (26).

LNs are critical organs for lipid trafficking, and decreased flow through the efferent lymphatics may

contribute to insulin resistance via altered lipid transport to the liver. Mass effect on the adjacent cortex

may affect cortical function as supported by studies showing decreased immune cell function in obese mice $(27,28)$. The adverse health impact of ectopic fat has also been identified in cancer outcomes. We

recently reported a positive association between fat enlarged axillary nodes and nodal metastasis among women with obesity who developed invasive breast cancer independent of BMI and tumor characteristics, supporting our hypothesis that ectopic nodal fat impacts nodal function as seen with ectopic adipose deposition in other organs (12). Our current study does not evaluate potential causal pathways, and additional studies are needed to better understand the relationship between ectopic nodal fat and cardiometabolic disease.

Our results show that ectopic fat in axillary LNs identified on screening mammograms is significantly associated with T2DM in both subgroups of women with and without obesity independent of BMI and age. The majority of women in the United States undergo screening mammography but do not undergo screening for cardiovascular disease (10). Maximizing screening tools for cardiometabolic disease promotes the identification of predominantly modifiable risk factors. The increasing incidence of obesityrelated cardiac and metabolic disease is leading to increased efforts to identify biomarkers of risk in order to target preventive and therapeutic interventions (29-32). While overwhelming evidence has shown that ectopic fat is a major contributor to cardiometabolic risk above and beyond BMI, the application of imaging tools to identify and quantify ectopic fat are currently not cost-effective. As a result, clinical assessment of ectopic adiposity remains challenging compared to easily obtained BMI. The ability to provide additional risk assessment for cardiometabolic disease by leveraging a highly utilized breast cancer screening exam could have significant clinical impact to promote lifestyle changes and disease prevention. 
Our study was the first to examine the association between fat-enlarged axillary LNs and cardiometabolic risk and has several limitations. First, we used a cross-sectional design, in which the status of cardiometabolic disease was retrieved from patients' problem list within three years of the screening mammogram. Because of the possible undiagnosed and unreported conditions on problem lists, the prevalence of cardiometabolic disease may be underestimated. Second, this pilot study included patients from a single institution, containing only mammograms with visible LNs. Although no appreciable difference has been reported among women with and without visible LNs, the feasibility and generalizability of studying axillary LNs can be limited by their visibility on screening mammograms. Despite variable mammographic LN visualization, the ability to leverage an existing screening study to opportunistically measure ectopic LN fat makes this technique potentially scalable and low cost. Our study confirms the finding in prior studies showing a strong association between fatty nodes and obesity and suggests that fat-enlarged LNs may represent a novel ectopic fat depot. If further validated with larger datasets from external institutions, fatty LN status on screening mammography may become a novel imaging biomarker to improve risk assessment for T2DM in clinical practice.

\section{Conclusion}

In conclusion, we observed a significant association between fat-enlarged axillary LNs and T2DM among 834 women with visible axillary LNs on screening mammograms that was independent of age and BMI. The identification of fat-enlarged axillary lymph nodes could potentially improve the prediction of T2DM.

\section{References}

1. Cercato C, Fonseca FA. Cardiovascular risk and obesity. Diabetology \& Metabolic Syndrome. 2019 Aug 28;11(1):74.

2. Koliaki C, Liatis S, Kokkinos A. Obesity and cardiovascular disease: revisiting an old relationship. Metabolism. 2019 Mar 1;92:98-107. 
3. Landsberg L, Aronne LJ, Beilin LJ, Burke V, Igel LI, Lloyd-Jones D, et al. Obesity-Related Hypertension: Pathogenesis, Cardiovascular Risk, and Treatment. The Journal of Clinical Hypertension. 2013;15(1):14-33.

4. Després J-P. Body Fat Distribution and Risk of Cardiovascular Disease. Circulation. 2012 Sep 4;126(10):1301-13.

5. Neeland IJ, Poirier P, Després J-P. Cardiovascular and Metabolic Heterogeneity of Obesity: Clinical Challenges and Implications for Management. Circulation. 2018 Mar 27;137(13):1391-406.

6. Britton KA, Massaro JM, Murabito JM, Kreger BE, Hoffmann U, Fox CS. Body fat distribution, incident cardiovascular disease, cancer, and all-cause mortality. J Am Coll Cardiol. 2013 Sep 3;62(10):921-5.

7. Lettner A, Roden M. Ectopic fat and insulin resistance. Curr Diab Rep. 2008 Jun;8(3):185-91.

8. Gastaldelli A. Role of beta-cell dysfunction, ectopic fat accumulation and insulin resistance in the pathogenesis of type 2 diabetes mellitus. Diabetes Res Clin Pract. 2011 Aug;93 Suppl 1:S60-65.

9. diFlorio Alexander RM, Haider SJ, MacKenzie T, Goodrich ME, Weiss J, Onega T. Correlation between obesity and fat-infiltrated axillary lymph nodes visualized on mammography. Br J Radiol. 2018 Sep;91(1089):20170110.

10. Chang JM, Leung JWT, Moy L, Ha SM, Moon WK. Axillary Nodal Evaluation in Breast Cancer: State of the Art. Radiology. 2020 Apr 21;295(3):500-15.

11. Keshavarz E, Ahangaran A, Pouya EK, Maheronnaghsh R, Chavoshi M, Rouzrokh P. Effects of Obesity on Axillary Lymph Node Structure: Association of Hilar Fat Deposition and Alterations in Cortex Width. Maedica (Bucur). 2020 Mar;15(1):99-104.

12. diFlorio-Alexander RM, Song Q, Dwan D, Austin-Strohbehn JA, Muller KE, Kinlaw WB, et al. Fat-enlarged axillary lymph nodes are associated with node-positive breast cancer in obese patients. Breast Cancer Res Treat [Internet]. 2021 Jun 3 [cited 2021 Jun 16]; Available from: https://doi.org/10.1007/s10549-021-06262-z

13. Snel M, Jonker JT, Schoones J, Lamb H, de Roos A, Pijl H, et al. Ectopic Fat and Insulin Resistance: Pathophysiology and Effect of Diet and Lifestyle Interventions. International Journal of Endocrinology. 2012 May 24;2012:e983814.

14. Piché M-E, Tchernof A, Després J-P. Obesity Phenotypes, Diabetes, and Cardiovascular Diseases. Circ Res. 2020 May 22;126(11):1477-500.

15. Neeland IJ, Turer AT, Ayers CR, Powell-Wiley TM, Vega GL, Farzaneh-Far R, et al. Dysfunctional Adiposity and the Risk of Prediabetes and Type 2 Diabetes in Obese Adults. JAMA. 2012 Sep 19;308(11):1150-9.

16. Ballestri S, Nascimbeni F, Romagnoli D, Lonardo A. The independent predictors of non-alcoholic steatohepatitis and its individual histological features.: Insulin resistance, serum uric acid, metabolic syndrome, alanine aminotransferase and serum total cholesterol are a clue to pathogenesis and candidate targets for treatment. Hepatol Res. 2016 Oct;46(11):1074-87. 
17. Sattar N, Gill JM. Type 2 diabetes as a disease of ectopic fat? BMC Medicine. 2014 Aug 26;12(1):123.

18. Okamura T, Hashimoto Y, Hamaguchi M, Obora A, Kojima T, Fukui M. Ectopic fat obesity presents the greatest risk for incident type 2 diabetes: a population-based longitudinal study. Int $\mathbf{J}$ Obes (Lond). 2019 Jan;43(1):139-48.

19. Levelt E, Pavlides M, Banerjee R, Mahmod M, Kelly C, Sellwood J, et al. Ectopic and Visceral Fat Deposition in Lean and Obese Patients With Type 2 Diabetes. J Am Coll Cardiol. 2016 Jul 5;68(1):53-63.

20. De Lorenzo A, Soldati L, Sarlo F, Calvani M, Di Lorenzo N, Di Renzo L. New obesity classification criteria as a tool for bariatric surgery indication. World J Gastroenterol. 2016 Jan 14;22(2):681-703.

21. Boutin RD, Lenchik L. Value-Added Opportunistic CT: Insights Into Osteoporosis and Sarcopenia. AJR Am J Roentgenol. 2020 Sep;215(3):582-94.

22. White A. Cancer Screening Test Use - United States, 2015. MMWR Morb Mortal Wkly Rep [Internet]. 2017 [cited 2021 Sep 22];66. Available from: https://www.facebook.com/cdcmmwr

23. National Center for Health Statistics (US). Health, United States, 2016: With Chartbook on Longterm Trends in Health [Internet]. Hyattsville (MD): National Center for Health Statistics (US); 2017 [cited 2021 Sep 22]. (Health, United States). Available from:

http://www.ncbi.nlm.nih.gov/books/NBK453378/

24. Sep 26 P, 2019. Coverage of Breast Cancer Screening and Prevention Services [Internet]. KFF. 2019 [cited 2021 Sep 22]. Available from: https://www.kff.org/womens-health-policy/factsheet/coverage-of-breast-cancer-screening-and-prevention-services/

25. Karsa L von, Anttila A, Ronco G, Ponti A, Malila N, Arbyn M, et al. Cancer screening in the European Union. Report on the implementation of the Council Recommendation on cancer screening. Cancer screening in the European Union Report on the implementation of the Council Recommendation on cancer screening [Internet]. 2008 [cited 2021 Sep 22]; Available from: https://www.cabdirect.org/cabdirect/abstract/20093115601

26. Chughtai HL, Morgan TM, Rocco M, Stacey B, Brinkley TE, Ding J, et al. Renal sinus fat and poor blood pressure control in middle-aged and elderly individuals at risk for cardiovascular events. Hypertension. 2010 Nov;56(5):901-6.

27. Kim CS, Lee SC, Kim YM, Kim BS, Choi HS, Kawada T, et al. Visceral fat accumulation induced by a high-fat diet causes the atrophy of mesenteric lymph nodes in obese mice. Obesity (Silver Spring). 2008 Jun;16(6):1261-9.

28. Geys L, Vranckx C, Lijnen HR, Scroyen I. CD36 deficiency blunts effects of diet on regulatory T cells in murine gonadal adipose tissue and mesenteric lymph nodes. Cell Immunol. 2015 Dec;298(1-2):33-6.

29. Ndisang JF, Rastogi S. Cardiometabolic Diseases and Related Complications: Current Status and Future Perspective. BioMed Research International. 2013 Oct 9;2013:e467682. 
medRxiv preprint doi: https://doi.org/10.1101/2021.11.16.21266413; this version posted November 20, 2021. The copyright holder for this preprint (which was not certified by peer review) is the author/funder, who has granted medRxiv a license to display the preprint in perpetuity.

It is made available under a CC-BY-NC 4.0 International license.

30. Obesity and overweight [Internet]. [cited 2021 Jul 27]. Available from: https://www.who.int/newsroom/fact-sheets/detail/obesity-and-overweight

31. Malik VS, Willett WC, Hu FB. Global obesity: trends, risk factors and policy implications. Nat Rev Endocrinol. 2013 Jan;9(1):13-27.

32. Han JC, Lawlor DA, Kimm SYS. Childhood obesity. Lancet. 2010 May 15;375(9727):1737-48. 


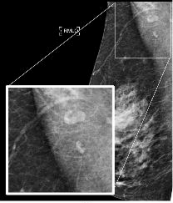

(a)

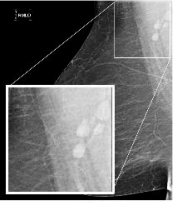

(c)

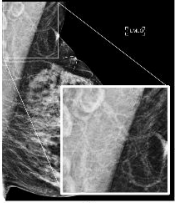

(b)

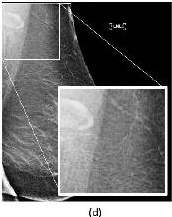




\section{Whermes ine}

crim naveda. cous-soces.

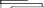

10 mersi rets rom

orint

care14 14 new

IPreilise 


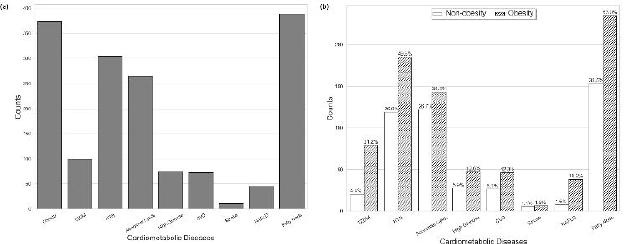


Unadjusted OR

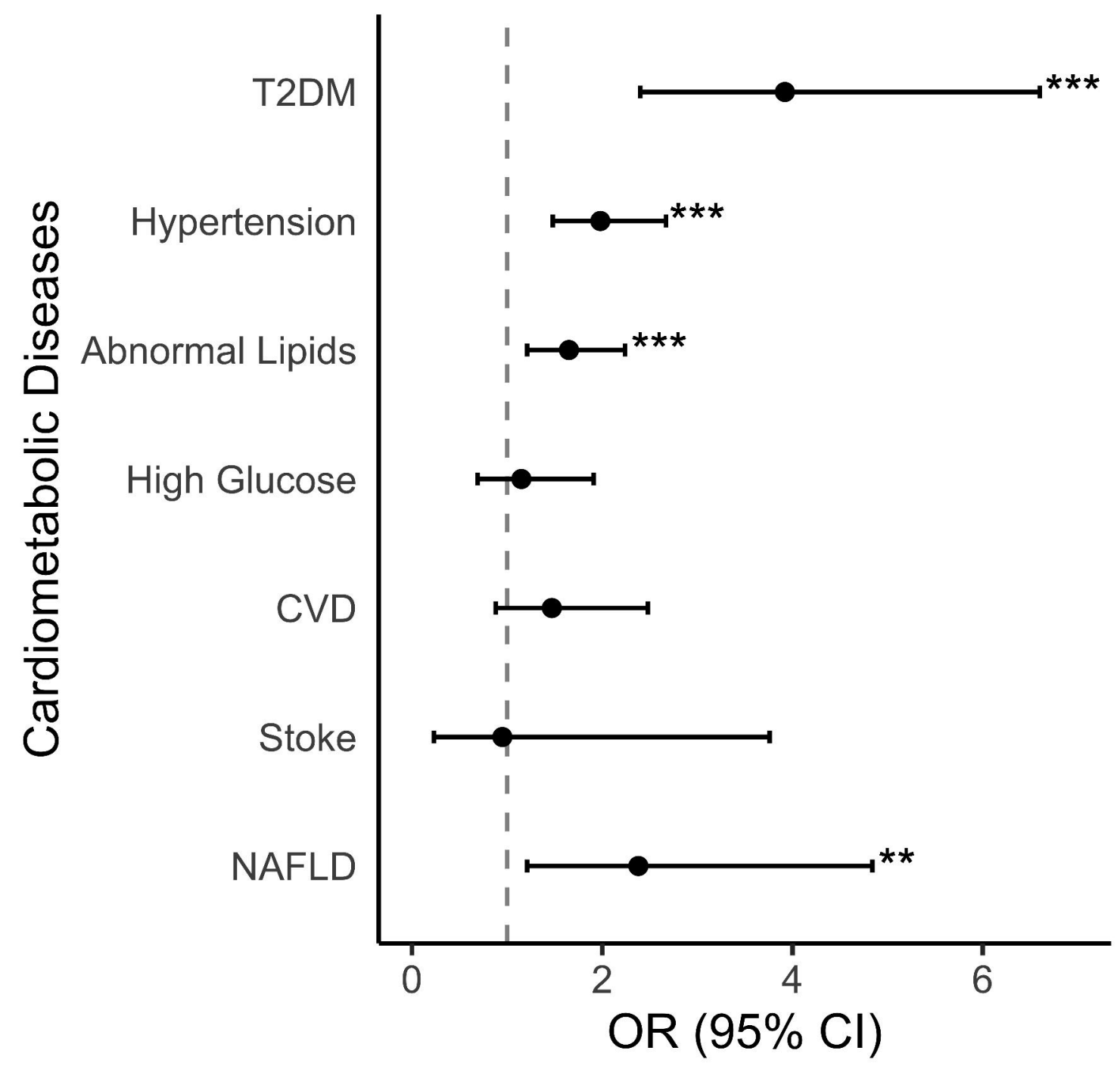

Adjusted OR

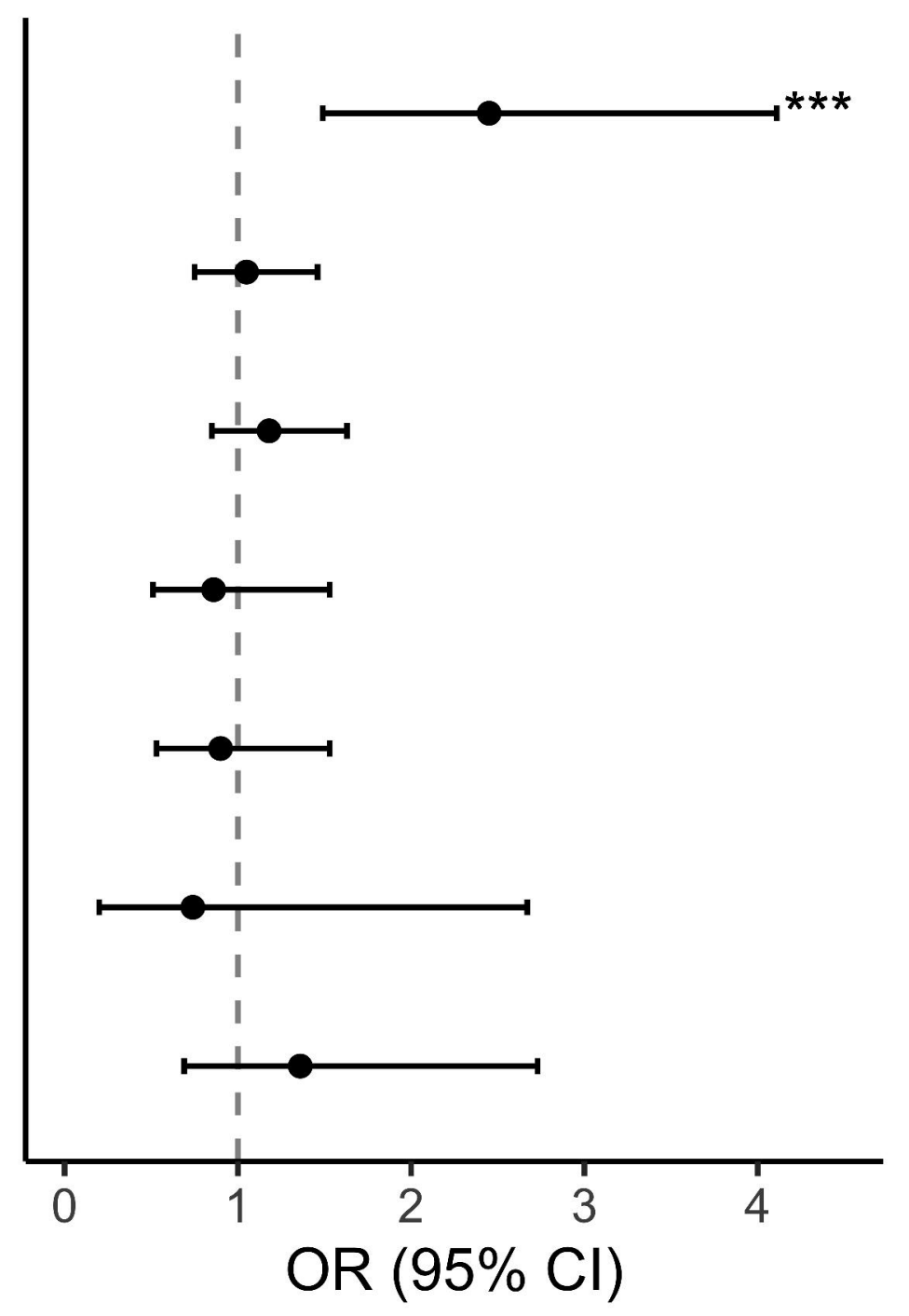

